Article

\title{
Air Quality in Windsor (Canada) and Impact of Regional Scale Transport
}

\author{
Tianchu Zhang, Yangfan Chen, Rongtai Tan and Xiaohong Xu *
}

Citation: Zhang, T.; Chen, Y.; Tan, R.; $\mathrm{Xu}, \mathrm{X}$. Air Quality in Windsor (Canada) and Impact of Regional Scale Transport. Atmosphere 2021, 12, 1300. https://doi.org/10.3390/ atmos12101300

Academic Editors: Yun Zhu, Jim Kelly, Jun Zhao, Jia Xing and Yuqiang Zhang

Received: 10 September 2021

Accepted: 4 October 2021

Published: 6 October 2021

Publisher's Note: MDPI stays neutral with regard to jurisdictional claims in published maps and institutional affiliations.

Copyright: (c) 2021 by the authors. Licensee MDPI, Basel, Switzerland. This article is an open access article distributed under the terms and conditions of the Creative Commons Attribution (CC BY) license (https:/ / creativecommons.org/licenses/by/ $4.0 /)$.
Department of Civil and Environmental Engineering, University of Windsor, Windsor, ON N9B 3P4, Canada; zhang14g@uwindsor.ca (T.Z.); chen196@uwindsor.ca (Y.C.); tan41@uwindsor.ca (R.T.)

* Correspondence: xxu@uwindsor.ca

\begin{abstract}
Air Quality Health Index (AQHI) is a scale designed in Canada to help residences understand the impact of air quality on health. This study investigated temporal variability of daily AQHI and impact of regional transport on AQHI in Windsor, Ontario, Canada from 2016 to 2019. The four-year average daily AQHI was 2.9, slightly below the upper limit of the low health risk level of 3. AQHI value decreased from 2.95 to 2.81 during the study period, indicating the improvement of air quality. Half of the days, AQHI were 3 regardless of season. AQHI was higher in the warm season (3.1) than in the cold season (2.6) due to more frequent moderate risk days $(27 \%, \mathrm{AQHI}=4)$ in warm season and more frequent low risk days $(42 \%, \mathrm{AQHI}=2)$ in the cold season. Among the three pollutants considered, $\mathrm{O}_{3}$ was the most frequently reported dominant contributor to daily AQHI ( $88 \%$ of days), followed by $\mathrm{NO}_{2}(12 \%)$, especially in the cold season, with small contribution from $\mathrm{PM}_{2.5}(<1 \%)$. Trajectory analysis found that AQHI $\leq 3$ days were closely associated with air masses from the north and northwest, whereas AQHI $>3$ days were closely associated with air masses from the west and southwest. This is because northerly flows brought in clear air mass owing to less industrial facilities. Polluted air masses were transported from the south of Windsor, where several industrial states of the US were located. Directional AQHI resembles $\mathrm{O}_{3}$ more than $\mathrm{NO}_{2}$ or $\mathrm{PM}_{2.5}$ concentrations do. Further improvement of AQHI in Windsor could be challenging because $\mathrm{O}_{3}$ concentrations have continued to increase in recent years. Thus, more effective control measures to mitigate $\mathrm{O}_{3}$ pollution are warranted to reduce its impact on human health and the environment.
\end{abstract}

Keywords: Air Quality Health Index (AQHI); air quality; regional transport; HYSPLIT; Windsor

\section{Introduction}

Air pollution is the biggest environmental risk to human health. Approximately $90 \%$ of the world population breathes air that does not meet the World Health Organization's air quality guidelines [1]. In 2015, the estimated worldwide premature death attributable to air pollution was 8.8 million people [2]. Major health effects include respiratory and cardiovascular illness through both short-term and long-term exposure to air pollution. Recent studies have observed those adverse health effects occurring at low concentration levels, suggesting no safe exposure levels, even at the otherwise considered relatively clean areas [3].

To assess air quality, monitoring stations have been in operation all over the world. As outlined in an Ontario Ministry of the Environment, Conservation and Parks (MECP) report [4], six air pollutants were considered in air quality index (AQI) in Canada. They are fine particulate matter $\left(\mathrm{PM}_{2.5}\right)$, ground-level ozone $\left(\mathrm{O}_{3}\right)$, nitrogen dioxide $\left(\mathrm{NO}_{2}\right)$, sulfur dioxides $\left(\mathrm{SO}_{2}\right)$, carbon monoxide $(\mathrm{CO})$ and total reduced sulfur compounds (TRS). The concentration of each pollutant was compared with its standard. The AQI is reported as the number corresponding to the concentration of a pollutant that is highest relative to its standard. When communicating with the public, the numeric AQI was classified into five descriptive categories: "very good", "good", "moderate", "poor" and "very poor" [4,5]. The AQI categories are often accompanied by corresponding health advice [4-6]. There 
are three key weaknesses associated with the AQI: (1) the inability to capture the overall health effects of multiple pollutants due to reliance on the worst offending pollutant, (2) the inability to reflect the apparent no-threshold concentration-response relationship between air pollution and human health, and (3) a lack of well-developed health messages [3,5,7].

To overcome the limitations of AQI, Health Canada and Environment Canada have developed a numerical index called Air Quality Health Index (AQHI), which represents the local air quality and its health impact on residents' health. The AQHI values are derived by drawing on two modes of assessment: (1) measuring the cumulative health effects of three pollutants- $\mathrm{O}_{3}, \mathrm{PM}_{2.5}$ and $\mathrm{NO}_{2}$ [3], and (2) observing short-term health effects in terms of mortality or morbidity using exposure-response relationship between air pollution and health from a time-series study of 12 major cities in Canada. These three pollutants were selected because they best represented health risks based on epidemiologic studies conducted in Canada [3]. In comparison with AQI, AQHI is readily understood by non-expert; therefore, it is easier to communicate the air pollution health risks to the public, especially presenting separate messages for the at risk and the general populations $[5,7]$. Researchers in other countries, including China [8,9] and Sweden [10], have explored the constructions of air quality health indexes using pollutant concentrations and riskcoefficients of different health outcomes obtained from local health datasets.

In Ontario, Canada, AQHI has been implemented since June 2015 to replace AQI [4]. While the incorporation of three contaminants- $\mathrm{O}_{3}, \mathrm{PM}_{2.5}$ and $\mathrm{NO}_{2}-$ effectively captures the health impact of air pollution mixtures, the impact of regional transport on local air quality could be less apparent due to a strong influence of local emissions and a relatively short atmospheric lifetime of $\mathrm{NO}_{2}$ (approximately hours). The objective of this study is to evaluate the temporal variability of $\mathrm{AQHI}$ and the impact of regional transport on air quality in Windsor, Ontario, Canada during the period of 2016-2019 by using observed $\mathrm{AQHI}, \mathrm{O}_{3}, \mathrm{PM}_{2.5}$ and $\mathrm{NO}_{2}$ concentrations and trajectory modeling. Windsor was selected as the study city because it is at the Canada-U.S. border. Transboundary sources contributed to over $80 \%$ of the annual $\mathrm{PM}_{2.5}$ concentrations and nearly $40 \%$ of ozone levels on high ozone concentration days [4].

\section{Method}

\subsection{Data Source and General Statistics}

There are two monitoring stations in Windsor: Windsor Downtown Station and Windsor West Station. The Windsor Downtown Station (Figure 1) was chosen because it is in a more densely populated area and therefore is more likely to have an impact on human life. Daily AQHI values from 2016 to 2019 were downloaded from Ontario's AQHI Historical Data Archive [11]. The hourly index values were calculated using $\mathrm{O}_{3}, \mathrm{PM}_{2.5}$ and $\mathrm{NO}_{2}$ concentrations and rounded to the nearest non-zero integers. The AQHI value at 4 p.m. local time was designated as daily AQHI by Ontario MECP [12]. There are four AQHI categories: (1) values between 1-3 are considered low risk, (2) 4-6 are moderate risk, (3) 7-10 are high risk and (4) greater than 10 are very high risk [4,5,7]. Hourly concentrations of $\mathrm{O}_{3}, \mathrm{PM}_{2.5}$ and $\mathrm{NO}_{2}$ were downloaded from National Air Pollution Surveillance Program website [12]. Four-year, annual, warm (April to September) and cold (October to March) seasons average AQHI values were calculated. The number of days with different $\mathrm{AQHI}$ values from one to seven was counted. 


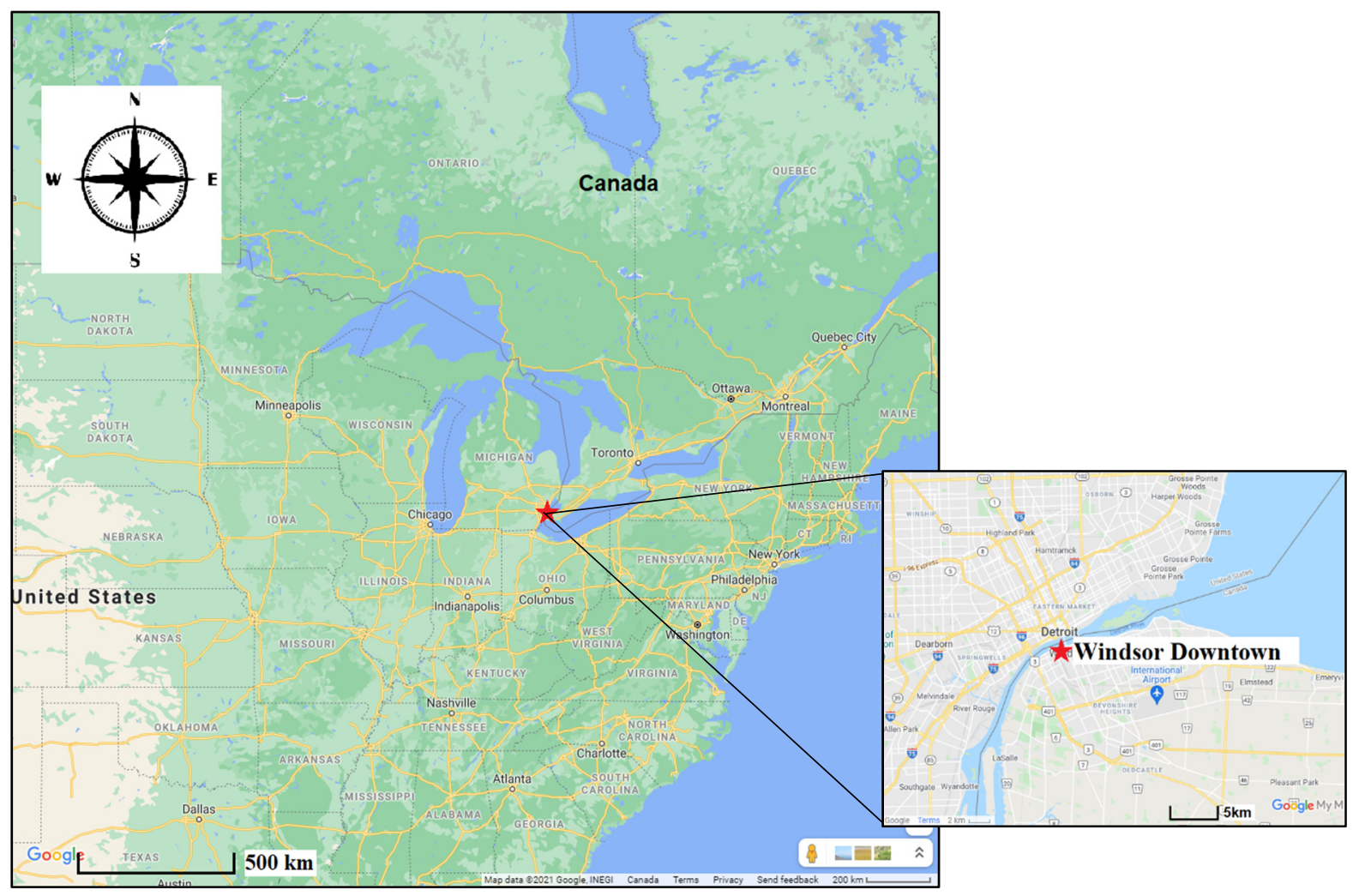

Figure 1. Windsor Downtown AQHI monitoring station (red star) in Windsor, Ontario (base maps adapted from Google Maps, coordinates of the station from MECP [4]).

\subsection{Air Trajectory Simulation}

The internet-based Hybrid Single Particle Lagrangian Integrated Trajectory (HYSPLIT) model [13] was used to simulate 24-h backward trajectory of each day with AQHI available from 2016 to 2019. HYSPLIT's backward trajectory model simulates the air mass's motion routes before they arrive at a particular start point $[14,15]$. The model has been widely employed to investigate regional transport of air pollutants [16-19].

The North American Mesoscale Forecast System (NAM) $12 \mathrm{~km}$ meteorological dataset was used because of its high spatial resolution. The start point is Windsor Downtown Station $\left(42.316^{\circ} \mathrm{N}, 83.0437^{\circ} \mathrm{W}\right)$. The start time was set at 4:00 p.m. local time when daily AQHI was calculated. The start height of trajectory was half of the boundary layer height, and the run time of 24-h was selected to represent regional transport and take into consideration the relatively short atmospheric lifetimes of $\mathrm{NO}_{2}$ and $\mathrm{O}_{3}$. In addition to graphic trajectory files, outputs in Google Earth $(\mathrm{kmz})$ format were saved.

\subsection{Analysis of Trajectories}

The trajectories were analyzed to investigate the association between air mass movement and air quality in Windsor during the cold season and the warm season from 2016 to 2019. Each trajectory was classified into four groups according to the AQHI value of that date: (1) $\mathrm{AQHI}<3,(2) \mathrm{AQHI}=3$, (3) $\mathrm{AQHI}=4$ and (4) $\mathrm{AQHI}=5$. Each group of trajectories were displayed on a Google Earth map to enable assessment of air mass origins and pathways, as well as comparison among the four AQHI groups.

The direction of each back trajectory was recorded by overlaying it on a compass with 36-bins in $10^{\circ}$ intervals. When a 24-h trajectory passed through several 10-degree sectors, only the first segment $(0-6 \mathrm{~h})$ of the trajectory was used to determine the direction of the air mass. An example is shown in Figure S1. The 36 directional average AQHI and $\mathrm{O}_{3}, \mathrm{PM}_{2.5}$, and $\mathrm{NO}_{2}$ concentrations used to calculate the AQHI at 4 p.m. local time 
were computed, and the percentages of trajectories from different directions were calculated for each air mass direction. The 36 air mass directions were further classified into eight categories: (1) north $\left(340-20^{\circ}\right)$, (2) northeast $\left(30-60^{\circ}\right)$, (3) east $\left(70-110^{\circ}\right)$, (4) southeast $\left(120-150^{\circ}\right),(5)$ south $\left(160-200^{\circ}\right),(6)$ southwest $\left(210-240^{\circ}\right)$, (7) west $\left(250-290^{\circ}\right)$ and (8) northwest $\left(300-330^{\circ}\right)$.

\section{Results and Discussion}

\subsection{General Assessment of Air Quality in Windsor}

The four-year average AQHI was 2.9, slightly lower than the upper limit of the low health risk level of 3 , indicating air quality in Windsor was fairly good with relatively low health risk. However, the AQHI value is likely higher compared with other stations in Ontario. Liang et al. [20] report that two regions registered the highest annual mean AQHI values (2.8-3.0) in Ontario in 2014: the central east region, which includes Toronto, and the southwest region, which includes Windsor. During 2016-2019, 1428 daily AQHIs were recorded in Windsor Downtown Station. Among those, the AQHIs were at the low health risk level (AQHI $=1,2$ or 3 ) in $82 \%$ of days, only a few days at high risk level $(\mathrm{AQHI}=7)$, the rest were at moderate health risk level $(\mathrm{AQHI}=4,5,6)$ (Figure 2a). This is consistent with data that the Ministry of the Environment and Climate Change collected in 2018, which suggests that low risk air quality hours occurred $93 \%$ of the time, followed by moderate risk hours $(7 \%)$, with fewer high-risk hours $(<1 \%)$ in Ontario [21] The year-to-year variability was small with annual means decreasing from 2.95 in 2016 to 2.81 in 2019 . AQHI was higher in the warm season than that during the cold season (3.1 vs. 2.6). This is because there were more moderate-risk days $(27 \%, \mathrm{AQHI}=4)$ in the warm season and more frequent low-risk days $(42 \%, \mathrm{AQHI}=2)$ in the cold season. This is attributable to two reasons, (1) $\mathrm{O}_{3}$ concentrations were higher in the warm season due to higher ambient temperature and intense solar radiation, and (2) $\mathrm{O}_{3}$ was the primary contributor to AQHI in Windsor ( $88 \%$ of days). Similar seasonal trends of AQHI have been reported by To et al. [22] using AQHI data at 42 stations in Ontario during 2003-2010 with higher AQHI values in spring $(3.8 \pm 1.1)$ and summer $(3.73 \pm 1.4)$ and lower AQHI in fall $(3.0 \pm 1.1)$ and winter $(3.3 \pm 1.0)$. As shown in Figure $2 b, c$, half of the days AQHI were 3 regardless of season. However, AQHI value of 2 were more frequent in the cold season, while the warm season recorded more days with $\mathrm{AQHI}=4$ and all days with $\mathrm{AQHI}=5,6$ or 7 .

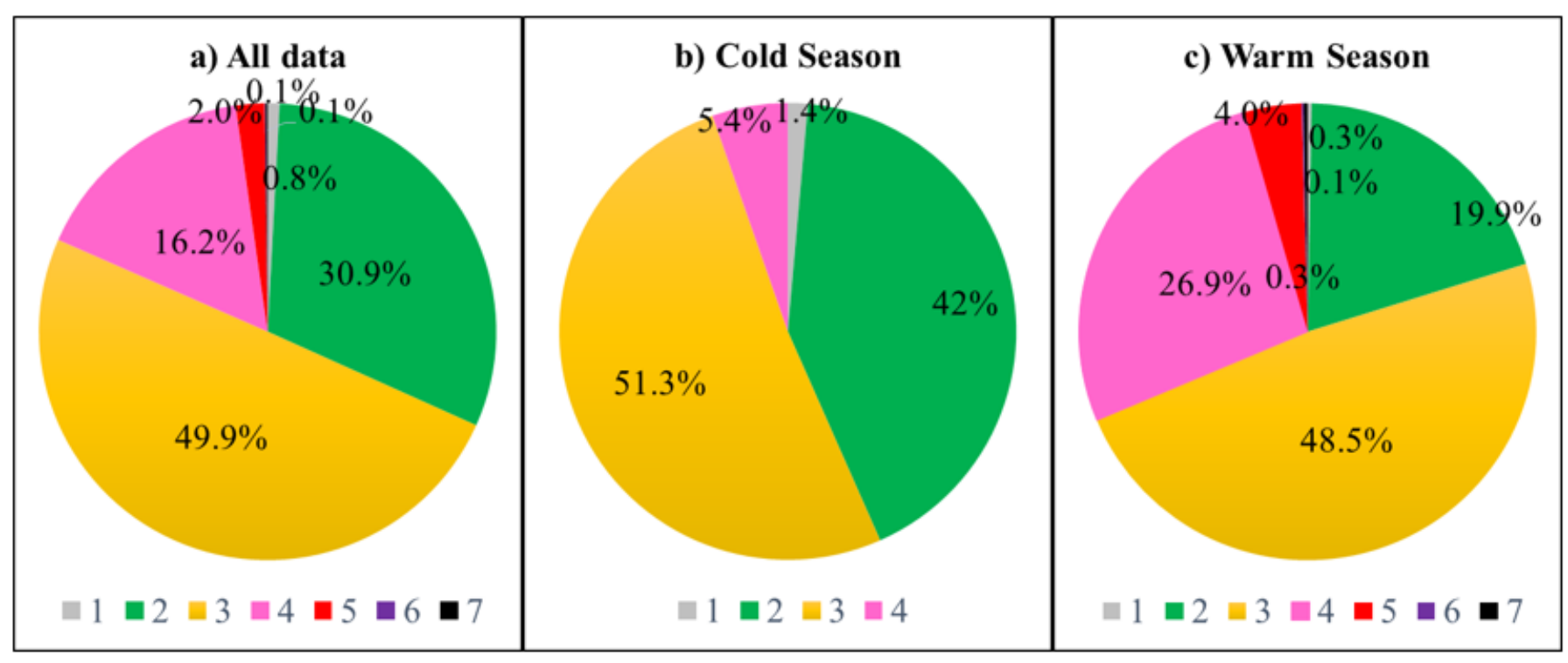

Figure 2. AQHI in Windsor during 2016-2019, (a) all days, (b) cold season, (c) warm season. 


\subsection{Back Trajectories by AQHI Group}

Days with AQHI values of 6 or 7 were excluded from further analysis due to the small sample size $(\mathrm{N}=3)$. The percentages of air mass directions in each AQHI group are illustrated in Figure 3. Figures 4-7 present back trajectory maps in each AQHI group. There were 453 back trajectories (green lines, Figure 4) with daily AQHI $<3$, twice as much in the cold season than in the warm season (308 vs. 145). Air masses came from all directions, but more trajectories and their 24-h endpoints were located in the area between the north and northwest of Windsor (Figure 3). Thus, low AQHI days were associated with clean air masses that originated from north and northwest of Windsor.

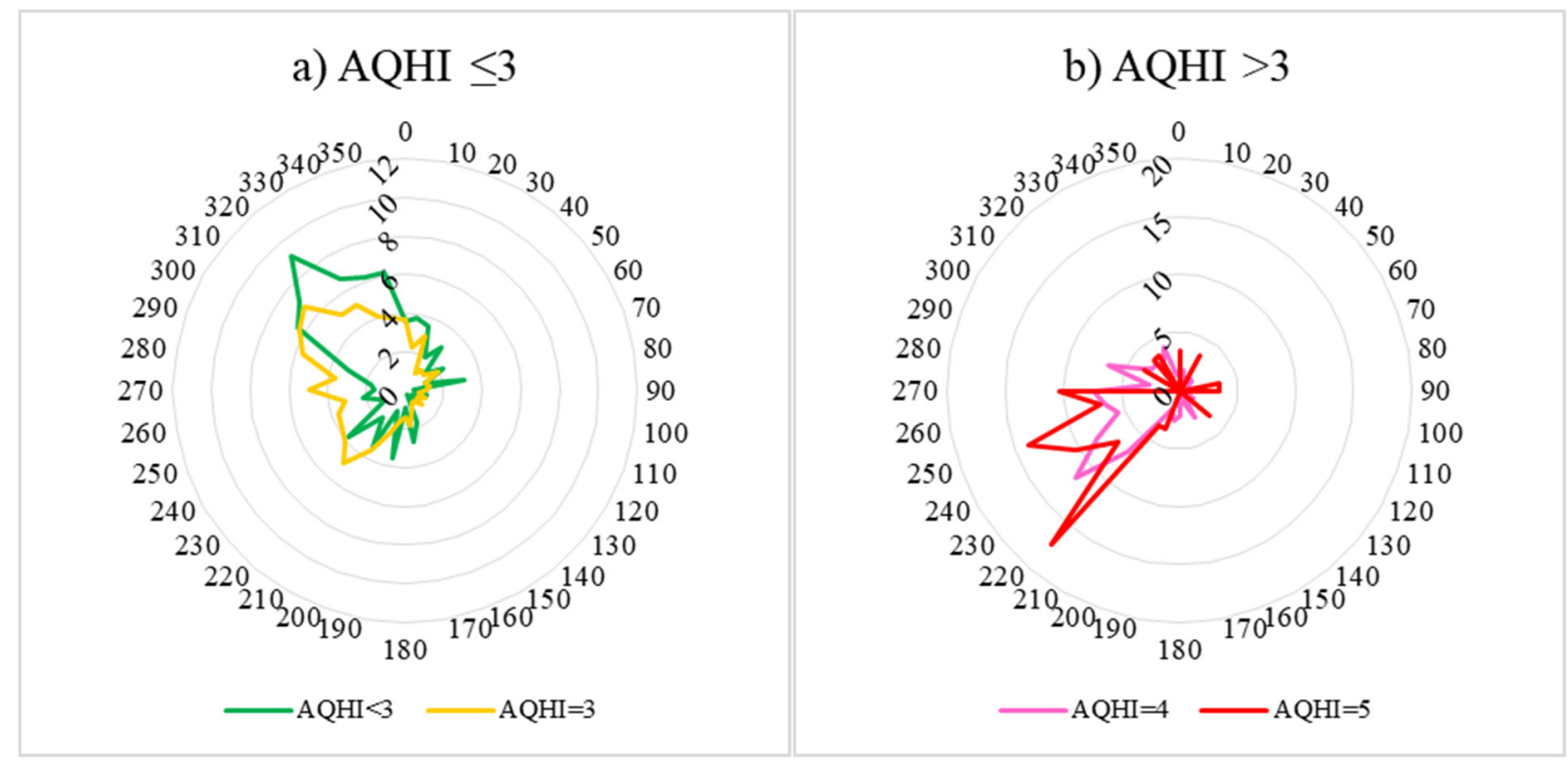

Figure 3. Percentage distribution (on vertical axis) of air-mass direction in each AQHI group.

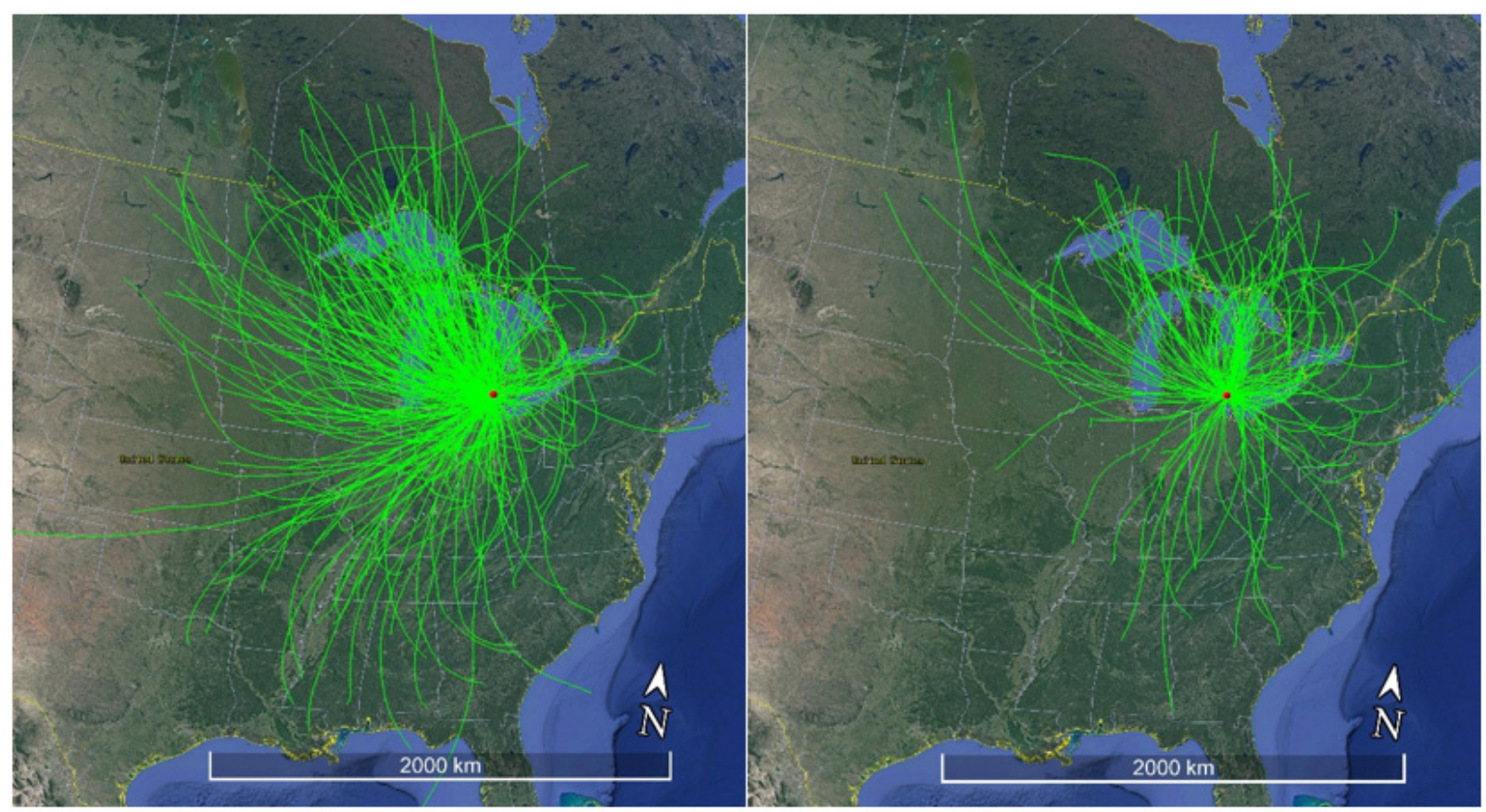

Figure 4. Back trajectories of $\mathrm{AQHI}<3$ days in cold season (left) and warm season (right). The red dot is Windsor. 


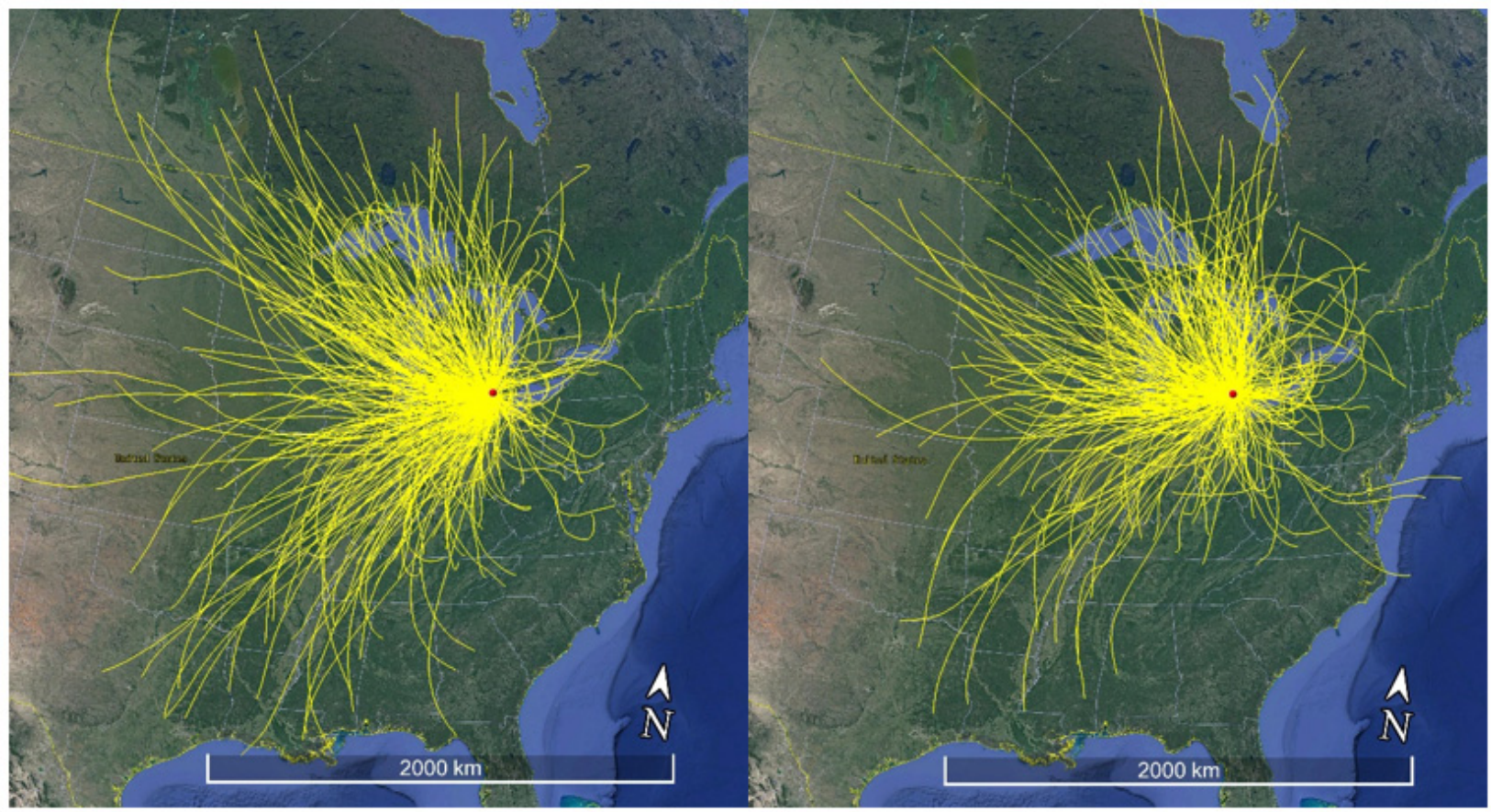

Figure 5. Back trajectories of $\mathrm{AQHI}=3$ days in cold season (left) and warm season (right). The red dots are Windsor.

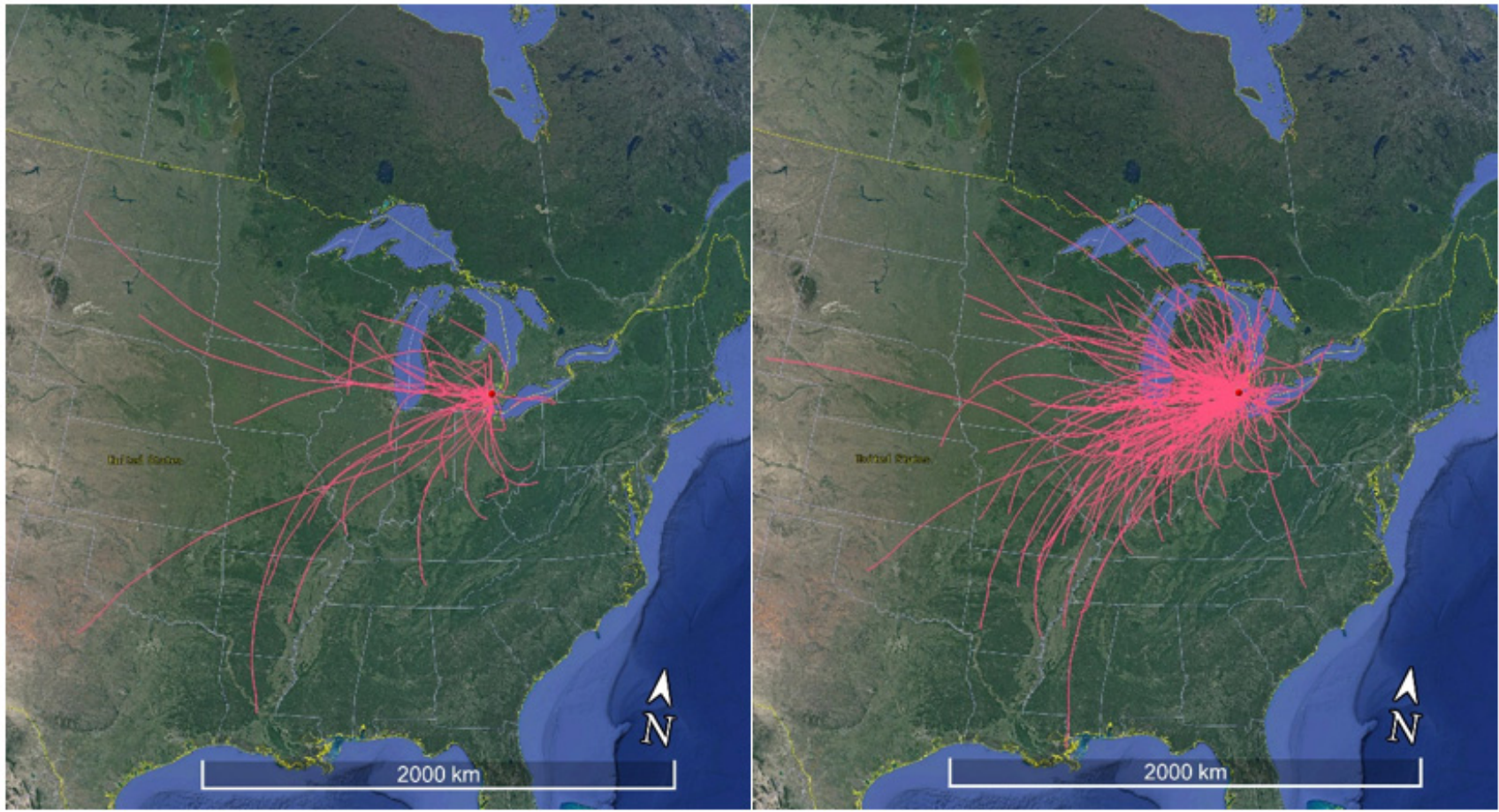

Figure 6. Back trajectories of $\mathrm{AQHI}=4$ days in cold season (left) and warm season (right). The red dot is Windsor. 


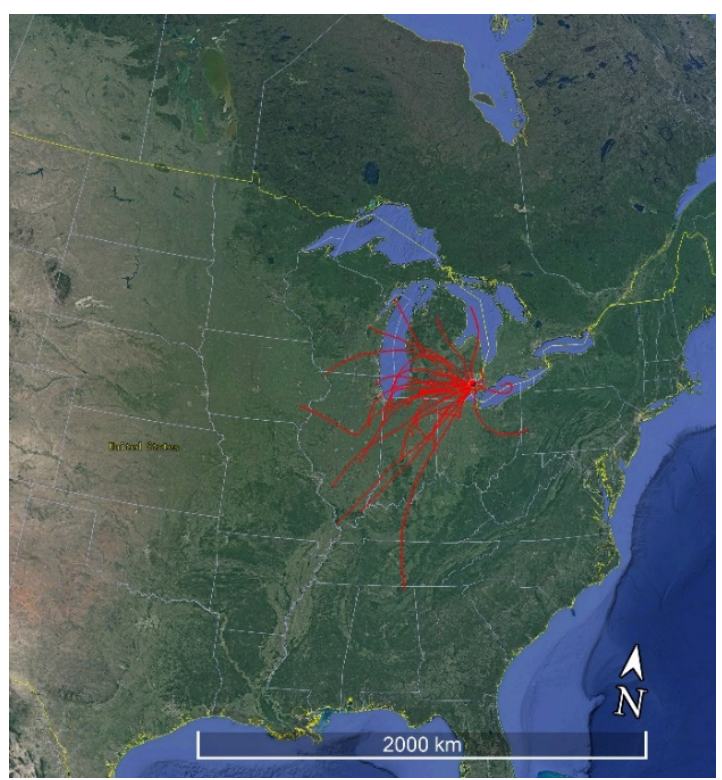

Figure 7. Back trajectories of $\mathrm{AQHI}=5$ days in warm season. The red dot is Windsor.

Figure 5 depicts back trajectories (348 in the warm season and 364 in the cold season) with $\mathrm{AQHI}=3$. Days with $\mathrm{AQHI}=3$ were associated more with air masses from the northwest, west and southwest. Compared to the AQHI $<3$ group, there were lower percentages of air masses from the northwest and higher percentages of air masses from the west and southwest (Figure 3), leading to slightly increased air pollution in Windsor, although $\mathrm{AQHI}=3$ is still a low-risk value. This is not unexpected because there are several industrial states of the US located in the south and southwest of Windsor (Figure 1); thus, regional transport of polluted air masses from these directions led to worse air quality $[19,23]$.

Figure 6 illustrates air trajectories (pink lines) with $\mathrm{AQHI}=4$, denoting that there were fewer in the cold season than in the warm season (38 vs. 193). The air mass origins and pathways are mainly observed on the west and southwest of Windsor (Figure 3). This was not unexpected because air masses from west and southwest brought polluted and hot air masses, leading to higher $\mathrm{O}_{3}$ concentrations in Windsor [19] and thus higher $\mathrm{AQHI}$ values. The Commission for Environmental Cooperation (CEC) also confirmed that long-range transport contributed significantly to $\mathrm{O}_{3}$ in eastern North America, specifically, pollutants being transported from the upper Midwest US and the Ohio River Valley across the Southern Ontario and the northeastern US [24].

Figure 7 shows back trajectories with $\mathrm{AQHI}=5$, all in the cold season. Five trajectories were from the north, east and southeast of Windsor; the remaining 24 trajectories were from the west and southwest of Windsor (Figure 3). Thus, polluted air masses were mainly from the west and southwest of Windsor leading to a relatively high AQHI value of 5 in Windsor. Further, the lengths of the 24-h trajectories are significantly shorter than those with $\mathrm{AQHI} \leq 4$ (Figures 4-6), indicating that slow moving air masses also contribute to polluted air due to weak dispersions. This is consistent with findings of a study of transboundary air pollution in Ontario. It was demonstrated that elevated $\mathrm{O}_{3}$ and $\mathrm{PM}_{2.5}$ are generally associated with slow-moving high-pressure systems in the lower Great Lakes area [23].

\subsection{Directional Average AQHIs and Pollutant Concentrations}

The prevailing air mass direction was southwest-west during the study period of 2016-2019 (Figure S2). Among the eight air mass directions, air masses from southeast, south, southwest and west directions (Figure 8 ) were more polluted, consequently, had a higher probability $(28-33 \%)$ of moderate health risk days $(\mathrm{AQHI} \geq 4)$ and a lower 
probability $(17-20 \%)$ of low health risk days (AQHI $\leq 2)$ than all other directions $(9-15 \%$ and $37-43 \%$, respectively). Approximately half $(45-55 \%)$ of the air masses were associated with $\mathrm{AQHI}=3$ regardless of directions. Consequently, $\mathrm{AQHI}=3$ could be considered the background levels. Since AQHI was 1 or 5 in few days (Figure 2), the directional average AQHI was controlled by the frequency of $\mathrm{AQHI}=2$ and $\mathrm{AQHI}=4$ days. This is consistent with directional $\mathrm{O}_{3}$ concentrations in Windsor, where higher $\mathrm{O}_{3}$ concentrations were associated with air masses from the south and west, whereas lower $\mathrm{O}_{3}$ concentrations were associated with air masses from the north [19].

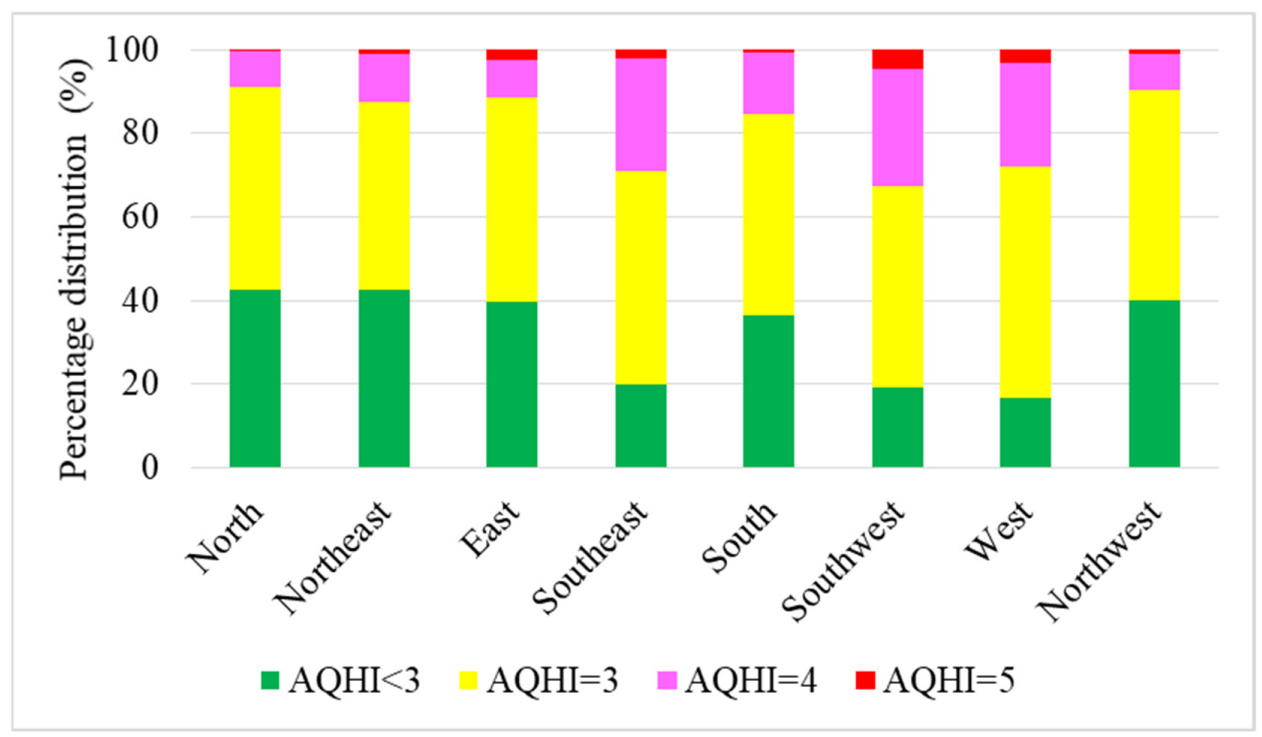

Figure 8. Percentage of different AQHI values in each of the eight air-mass directions.

The impact of air mass movement on Windsor air quality and AQHI is further demonstrated in Figure 9. $\mathrm{PM}_{2.5}$ concentrations were more sensitive to the air mass direction, with higher concentrations associated with air masses from the south to west direction. However, the distribution of AQHI closely resemble that of $\mathrm{O}_{3}$ concentrations. This is because, in $88.2 \%$ of days, $\mathrm{O}_{3}$ was the primary contributor to daily AQHI. There were 157 days ( $11.6 \%$ of all days) when $\mathrm{NO}_{2}$ was the primary contributor to $\mathrm{AQHI}$, and 154 of them were in the cold season (22\% of cold season days). $\mathrm{PM}_{2.5}$ was the primary contributor to AQHI in only two days, all in the cold season. The results of our analysis suggest that the daily AQHIs in Windsor reflect primarily the $\mathrm{O}_{3}$ concentrations and to a much lesser degree the $\mathrm{NO}_{2}$ concentrations in the cold season. Other evidence of daily AQHI being dictated by $\mathrm{O}_{3}$ concentrations include two patterns. First, the directional AQHI pattern (Figure 8) is consistent with directional $\mathrm{O}_{3}$ concentrations in Windsor presented by Zhang et al. [19], who found that lower $\mathrm{O}_{3}$ concentrations in Windsor were associated with air masses from the north, while higher $\mathrm{O}_{3}$ concentrations were associated with air masses from the south and southwest. Second, the seasonal AQHI pattern is in agreement with seasonal $\mathrm{O}_{3}$ concentrations reported by $\mathrm{Xu}$ et al. [25], who found that $\mathrm{O}_{3}$ concentrations were higher in summer and lower in winter. However, the strong dependency of $\mathrm{PM}_{2.5}$ concentrations on regional transport is not shown in directional AQHI. Compared with an analysis of AQHI data from 2003-2010 [5], the frequency of $\mathrm{NO}_{2}$ as the top contributor to daily AQHI has decreased substantially, from $51 \%$ to $12 \%$, while that of $\mathrm{O}_{3}$ has increased substantially, from $49 \%$ to $88 \%$. This is not unexpected because the annual mean $\mathrm{NO}_{2}$ had decreased significantly by $33 \%$, while annual mean $\mathrm{O}_{3}$ concentration had increased significantly by $6.4 \%$ during $2009-2018$ in Windsor [21]. Ontario experienced a $24 \%$ reduction in hourly AQHI value from 2003 to 2014 [20]. However, further improvement of $\mathrm{AQHI}$ in Windsor or other Ontario cities beyond the 2020 could be challenging. Using the $\mathrm{AQHI}$ formula in Stieb et al. [7], a $10 \%$ reduction of $\mathrm{NO}_{2}$ from $11 \mathrm{ppb}$ (the annual mean in 
Ontario in 2018 [21]) combined with a $10 \%$ increment of $\mathrm{O}_{3}$ from $27 \mathrm{ppb}$ (the annual mean in Ontario in 2018 [21]) lead to a $2.7 \%$ increase in AQHI.

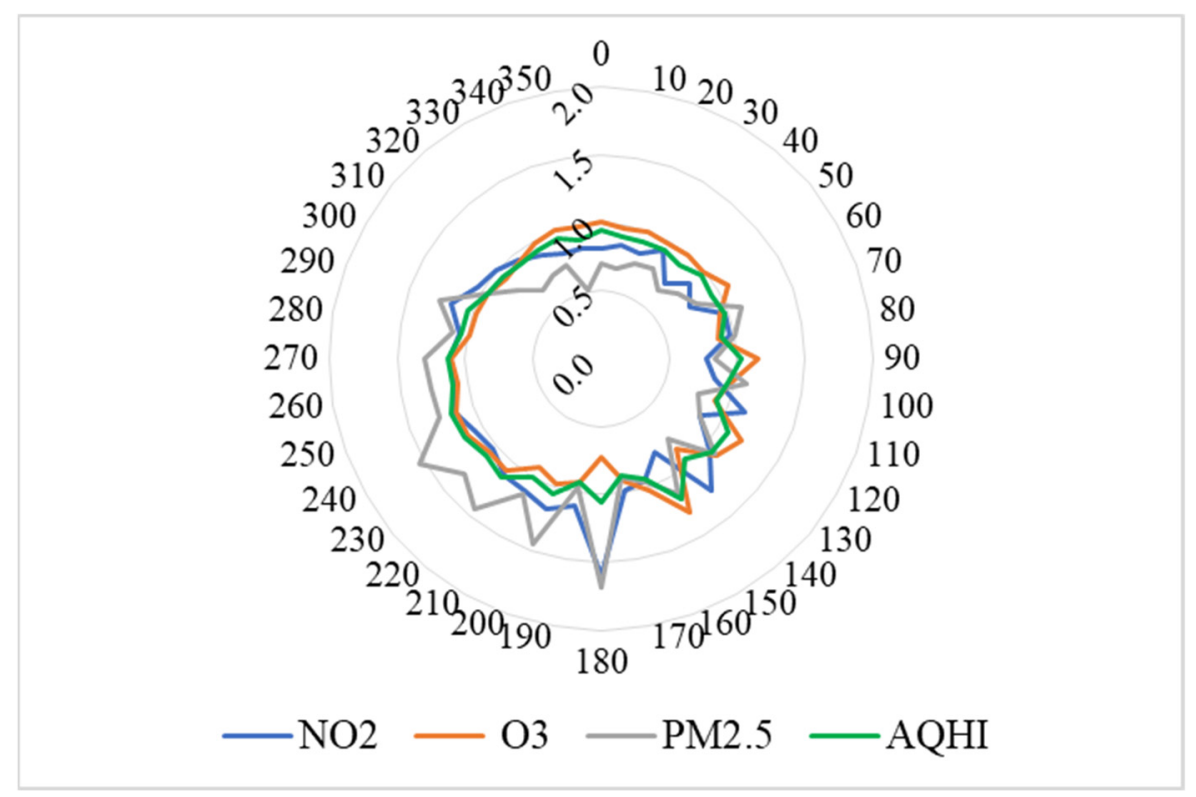

Figure 9. Directional AQHI and air pollutant concentrations, normalized to the perspective overall mean value, respectively.

\section{Conclusions}

The study investigated temporal variability of daily AQHI and the impact of regional transport on AQHI in Windsor from 2016 to 2019. The air quality was fairly good with a four-year average $\mathrm{AQHI}$ of 2.9 , indicating relatively low health risk. Improving air quality was observed in Windsor, with the annual AQHI decreased from 2.95 in 2016 to 2.81 in 2019. Daily AQHI was higher in the warm season (3.1) and lower in the cold season (2.6) due to more frequent $\mathrm{AQHI} \geq 4$ days in the warm season ( $31 \%$ vs. $5 \%)$ and more $\mathrm{AQHI} \leq 2$ days in the cold season ( $43 \%$ vs. $20 \%$ ). This trend is primary driven by two key factors: (1) the seasonal variability of ground-level $\mathrm{O}_{3}$ concentration with higher values in the warm season, and (2) $\mathrm{O}_{3}$ being the primary contributor to daily AQHI in Windsor in $88 \%$ of days.

Among the three pollutants considered, $\mathrm{O}_{3}$ was the dominant contributor to daily $\mathrm{AQHI}$, followed by $\mathrm{NO}_{2}$ especially in the cold season, with small contribution from $\mathrm{PM}_{2.5}$. In the past two decades, $\mathrm{NO}_{2}$ concentrations had decreased significantly and $\mathrm{O}_{3}$ concentrations had increased, resulting in daily $\mathrm{AQHI}$ being less reliance on $\mathrm{NO}_{2}$ (from $51 \%$ of days being the primary contributor during 2003-2010 to $12 \%$ during 2016-2019) and more on $\mathrm{O}_{3}$ concentrations ( $49 \%$ to $88 \%$ ).

HYSPLIT trajectories revealed daily AQHI was 3 in half of the days regardless of season or air mass direction. Air masses from west and southwest of Windsor had a higher probability (28-33\%) of greater AQHI values (4 or 5) and lower probability (17-20\%) of smaller AQHI values $(\leq 2)$ than other directions $(9-15 \%$ and $37-43 \%$, respectively). In other words, Windsor's air quality is strongly influenced by several industrial states of the US located in the west and southwest and polluted air masses are therefore being transported to Windsor through the prevailing wind direction. Further, the study hypothesis was accepted: The impact of regional transport on AQHI was less apparent. The strong dependency of $\mathrm{PM}_{2.5}$ concentrations on air mass direction was not reflected in the directional distribution of daily AQHI, which closely resembled that of $\mathrm{O}_{3}$ concentrations.

Overall, $\mathrm{O}_{3}$ concentrations dictate the daily $\mathrm{AQHI}$ values, the seasonal variability of AQHI, and the impact of regional transport on AQHI in Windsor. This makes further reductions of $\mathrm{AQHI}$ challenging because $\mathrm{O}_{3}$ concentrations will likely continue to increase 
as a result of weakened NO titration effect, which is a consequence of less consumption of $\mathrm{O}_{3}$ by $\mathrm{NO}$ [25] and more hot days because of climate change. The predominant and increasing contribution of $\mathrm{O}_{3}$ to AQHI calls for more effective control measures to mitigate $\mathrm{O}_{3}$ pollution and its impact on human health and the environment. Future studies should explore two important phenomena: (1) whether the seasonal trend of AQHI and the increasing reliance of $A Q H I$ on ambient $\mathrm{O}_{3}$ observed in Windsor have occurred in other Canadian cities, and (2) how the relative contributions of each AQHI related pollutant $\left(\mathrm{NO}_{2}, \mathrm{PM}_{2.5}\right.$ and $\left.\mathrm{O}_{3}\right)$ have evolved over time and the driving forces causing those changes.

Supplementary Materials: The following are available online at https:/ /www.mdpi.com/article/10 .3390 /atmos12101300/s1, Figure S1: Example of air trajectory direction measurement. The start is Windsor. The direction is recorded as 220 degrees, Figure S2: Wind rose at Windsor 2016-2019.

Author Contributions: Conceptualization, methodology, funding acquisition, supervision, project administration, X.X.; data curation and model simulations, Y.C., R.T.; writing-original draft preparation, review and editing, T.Z., X.X.; visualization, T.Z., Y.C. All authors have read and agreed to the published version of the manuscript.

Funding: This research was funded by the Natural Sciences and Engineering Research Council of Canada.

Data Availability Statement: Publicly available datasets were analyzed in this study. Daily AQHI values in Windsor, Ontario during 2016-2019 can be found at: http:/ / www.airqualityontario.com/ aqhi/search.php. Hourly $\mathrm{O}_{3}, \mathrm{PM}_{2.5}$, and $\mathrm{NO}_{2}$ concentrations in Windsor, Ontario during 2016-2019 can be found at: https: / / data.ec.gc.ca/data/air/monitor/national-air-pollution-surveillance-napsprogram/Data-Donnees/?lang=en.

Acknowledgments: The authors gratefully acknowledge the NOAA Air Resources Laboratory (ARL) for the provision of the HYSPLIT transport and dispersion model and READY website ( http:/ / www.ready.noaa.gov, last accessed on 7 September 2021) used in this publication. The authors want to thank Jason Horn at University of Windsor for his assistance.

Conflicts of Interest: The authors declare no conflict of interest.

\section{References}

1. World Health Organization (WHO). Air pollution in the Western Pacific. 2020. Available online: https://www.who.int/ westernpacific/health-topics/air-pollution (accessed on 7 September 2021).

2. Lelieveld, J.; Pozzer, A.; Pöschl, U.; Fnais, M.; Haines, A.; Münzel, T. Loss of life expectancy from air pollution compared to other risk factors: A worldwide perspective. Cardiovasc. Res. 2020, 116, 1910-1917. [CrossRef] [PubMed]

3. Abelsohn, A.; Stieb, D.M. Health effects of outdoor air pollution: Approach to counseling patients using the Air Quality Health Index. Can. Fam. Physician 2011, 57, 881-887. [PubMed]

4. Ontario Ministry of the Environment. Conservation and Parks (MECP), 2017-Air quality in Ontario 2015 Report. Available online: http:/ / www.airqualityontario.com/downloads/AirQualityInOntarioReportAndAppendix2015.pdf (accessed on 7 September 2021).

5. Chen, H.; Copes, R. Review of Air Quality Index and Air Quality Health Index, Environmental and Occupation Health, Public Health Ontario. 2013. Available online: https://www.publichealthontario.ca/-/media/documents/A/2013/air-quality-healthindex.pdf (accessed on 7 September 2021).

6. United States Environmental Protection Agency (USEPA). What Is the U.S. Air Quality Index (AQI)? 2021. Available online: https:/ / www.airnow.gov/aqi/aqi-basics / (accessed on 7 September 2021).

7. Stieb, D.M.; Burnett, R.T.; Smith-Doiron, M.; Brion, O.; Shin, H.H.; Economou, V. A new multipollutant, no-threshold air quality health index based on short-term associations observed in daily time-series analyses. J. Air Waste Manag. Assoc. 2008, 58, 435-450. [CrossRef] [PubMed]

8. Chen, R.; Wang, X.; Meng, X.; Hua, J.; Zhou, Z.; Chen, B.; Kan, H. Communicating air pollution-related health risks to the public: An application of the Air Quality Health Index in Shanghai, China. Environ. Int. 2013, 51, 168-173. [CrossRef] [PubMed]

9. Du, X.; Chen, R.; Meng, X.; Liu, C.; Niu, Y.; Wang, W.; Li, S.; Kan, H.; Zhou, M. The establishment of national air quality health index in China. Environ. Int. 2020, 138, 105594. [CrossRef] [PubMed]

10. Olstrup, H. An Air Quality Health Index (AQHI) with different health outcomes based on the air pollution concentrations in Stockholm during the period of 2015-2017. Atmosphere 2020, 11, 192. [CrossRef]

11. Ontario Ministry of the Environment. Conservation and Parks (MECP). 2021-Air Quality Health Index (AQHI) Historical Search. Available online: http:/ / www.airqualityontario.com/aqhi/search.php (accessed on 7 September 2021). 
12. National Air Pollution Surveillance Program (NAPS). Data-Donnees. 2021. Available online: https:/ / data.ec.gc.ca/data/air/ monitor/national-air-pollution-surveillance-naps-program/Data-Donnees/?lang=en (accessed on 7 September 2021).

13. National Oceanic and Atmospheric Administration (NOAA). Air Resources Laboratory. 2021. Available online: https://www. ready.noaa.gov / HYSPLIT.php (accessed on 7 September 2021).

14. Rolph, G.; Stein, A.; Stunder, B. Real-time Environmental Applications and Display system: READY. Environ. Model. Softw. 2017, 95, 210-228. [CrossRef]

15. Stein, A.F.; Draxler, R.R.; Rolph, G.D.; Stunder, B.J.B.; Cohen, M.D.; Ngan, F. NOAA's HYSPLIT atmospheric transport and dispersion modeling system. Bull. Amer. Meteor. Soc. 2015, 96, 2059-2077. [CrossRef]

16. Jumbam, L.; Raffuse, S.M.; Wiedinmyer, C.; Larkin, N. Modeling Regional Air Quality Impacts from Indonesian Biomass Burning. In Proceedings of the AGU Fall Meeting, San Francisco, CA, USA, 3-7 December 2012; Volume 2012, p. A21A-0035.

17. Miller, L.; Farhana, S.; Xu, X. Trans-boundary air pollution in Windsor, Ontario (Canada). Procedia Environ. Sci. 2010, 2, 585-594. [CrossRef]

18. Shan, W.; Yin, Y.; Lu, H.; Liang, S.A. Meteorological analysis of ozone episodes using HYSPLIT model and surface data. Atmos. Res. 2009, 93, 767-776. [CrossRef]

19. Zhang, T.; Xu, X.; Su, Y. Impacts of Regional Transport and Meteorology on Ground-Level Ozone in Windsor, Canada. Atmosphere 2020, 11, 1111. [CrossRef]

20. Liang, S.; Zhu, J.; McGihon, R.; Terebessy, E.; Ge, E.; Su, Y.; Fong, I.; To, T. Visualizing and forecasting the association of air quality and health outcomes in Ontario, Canada. Can. Geogr. 2021, 65, 382-389. [CrossRef]

21. Ontario Ministry of the Environment and Climate Change (MOECC). 2021-Air Quality in Ontario 2018 Report. Available online: https:/ / www.ontario.ca/document/ air-quality-ontario-2018-report (accessed on 7 September 2021).

22. To, T.; Feldman, L.; Simatovic, J.; Gershon, A.S.; Dell, S.; Su, J.; Foty, R.; Licskai, C. Health risk of air pollution on people living with major chronic diseases: A Canadian population-based study. BMJ Open 2015, 5, e009075. [CrossRef]

23. Ontario Ministry of the Environment (MOE). Transboundary Air Pollution in Ontario. 2005. Available online: http://www. airqualityontario.com/downloads/TransboundaryAirPollutionInOntario2005.pdf (accessed on 7 September 2021).

24. Commission for Environmental Cooperation (CEC). Long-Range Transport of Ground Level Ozone and Its Precursors: Assessment of Methods to Quantify Transboundary Transport Within the Northeastern United States and Eastern Canada. 1997. Available online: http:/ / www3.cec.org/islandora/en/item/2185-long-range-transport-ground-level-ozone-and-its-precursors-en.pdf (accessed on 7 September 2021).

25. Xu, X.; Zhang, T.; Su, Y. Temporal variations and trend of ground-level ozone based on long-term measurements in Windsor, Canada. Atmos. Chem. Phys. 2019, 19, 7335-7345. [CrossRef] 